\title{
Potential role of ustekinumab in the treatment of chronic plaque psoriasis
}

\author{
This article was published in the following Dove Press journal: \\ Biologics: Targets \& Therapy \\ 10 May 2010 \\ Number of times this article has been viewed
}

\author{
Santo Raffaele Mercuri' \\ Luigi Naldi ${ }^{2}$ \\ 'Unità di Dermatologia, Istituto \\ di Ricovero e Cura a Carattere \\ Scientifico San Raffaele, Università \\ Vita-Salute, Milano, Italy; ${ }^{2}$ Centro \\ Studi GISED, Fondazione per la \\ Ricerca Ospedale Maggiore, Unità \\ di Dermatologia, Ospedali Riuniti, \\ Bergamo, Italy
}

\begin{abstract}
Psoriasis is a relatively common, chronic and disabling skin disease, with an immune-related pathogenesis and a genetic background which may be triggered by several environmental factors including smoking and infections. There is no cure but several treatment options are available. The treatment of psoriasis is far from being satisfactory due to impractical modalities of topical treatment and suboptimal safety profile of the systemic treatments available. In the last few years, parallel to an improved understanding of the disease pathogenesis, there has been a boost in research on new agents for the treatment of psoriasis. Ustekinumab, a monoclonal antibody targeting the p40 subunit of interleukin (IL)-12 and IL-23, is one such new agent. Psoriasis and its management are briefly reviewed before focusing on the evidence for ustekinumab in the treatment of chronic plaque psoriasis through a systematic search of the main registries of ongoing trials up to December 2009. Ustekinumab proved to be very effective short term in the control of clinical manifestations in psoriasis compared with placebo and with etanercept. Long-term and comparative data are still limited. There is a need for continuing research on the long-term effectiveness and safety of the drug.
\end{abstract}

Keywords: ustekinumab, chronic plaque psoriasis

Psoriasis is a chronic relapsing skin disease characterized, in the most usual form, namely chronic plaque psoriasis, by well demarcated erythematous and scaling plaques especially located on the extensory body areas and the scalp. The disease deeply affects well being and has emotional and relational consequences which go far beyond the skin. ${ }^{1}$ In addition, a link has been repeatedly suggested between the inflammatory process sustaining psoriasis and metabolic derangements. ${ }^{2}$ A number of diseases have been associated with psoriasis; in particular, arthritic manifestations in so-called psoriatic arthritis. ${ }^{3}$ A holistic approach, including education and psychological support, is needed for an optimal care of psoriatic patients. The main aim of the treatment is to reduce the burden of the disease over time, controlling symptoms, helping patients to cope with the chronic nature of the disease, limiting psychological and relational consequences, and preventing systemic complications and co-morbidity. Psoriasis is a disorder with a relatively high prevalence in the general population mainly as a result of its chronicity and the absence of a cure. Incidence rates are estimated to vary from 50 to 140 new cases per 100,000 people per year. Point prevalence estimates vary between $0.8 \%$ and $4 \%$ in different countries. ${ }^{4}$
Correspondence: Luigi Naldi Centro Studi GISED, Fondazione per la Ricerca Ospedale Maggiore, Presidio Ospedaliero Matteo Rota,Via Garibaldi I3/I5, 24100 Bergamo, Italy

$\mathrm{Tel}+39(0) 352278-719,-720$

Fax +39 (0) 352278673

Email luigi.naldi@gised.it 


\section{Psoriasis as a complex disorder Severity grading}

Agreement exists on the management value of distinguishing between nonpustular and pustular varieties. Among nonpulstular varieties, guttate and chronic plaque psoriasis can be considered, while both localized and generalized varieties of pustular psoriasis can be identified. A further distinction can be made between stable and transitional varieties, ie, unstable inflammatory psoriasis and erythroderma. Most of the clinical research on psoriasis has been restricted to chronic plaque psoriasis. The evidence for other clinical varieties is very limited. If not otherwise specified, we will make reference in the following discussion to chronic plaque psoriasis. At variance with many chronic disorders, psoriasis does not appear to progress steadily toward a definite outcome and hence it is difficult to split the disease into stages by natural history. Attempts at measuring disease severity have been largely limited to assessing the skin area involved with psoriatic lesions at a point in time and related clinical issues like the degree of scaling and infiltration. The prototype for such measures is the Psoriasis Area and Severity Index (PASI), which was developed as an outcome measure in clinical trials on oral retinoids in 1978. These indexes do not make any difference between different pattern distributions or clinical subgroups and are poorly suited to assess disease varieties other than chronic plaque psoriasis. ${ }^{5}$ Since psoriasis is a chronic disease, one crucial issue would be to assess it over a relevant time frame and not only at a point in time. In the long term, simple outcome measures applicable in all patients seem preferable. These may include clinical remission, number of hospital admissions or ambulatory consultations, and major disease flare-ups. A number of quality of life instruments have been designed to asses dermatologic conditions or, more specifically, psoriasis. The most popular ones are the Dermatology Life Quality Index (DLQI), the Psoriasis Disability Index (PSI), and the Psoriasis Life Stress Inventory (PLSI). ${ }^{6}$

A useful distinction should be made between severe psoriasis and psoriasis that severely affects quality of life. As pointed out recently, such a distinction has relevant consequences in terms of disease management. ${ }^{7}$ Patients with objectively mild psoriasis experiencing a disproportionate impact on quality of life may benefit from psychological support and learning coping strategies, rather than systemic drugs to suppress disease activity. Recently, a set of criteria were developed by the European Medicines Agency (EMEA) mainly for the purpose of standardizing assessment in randomized clinical trials. The system distinguishes mild psoriasis ( $<10 \%$ body surface area involved and manageable by topical agents) from moderate-severe and severe psoriasis (skin involvement is $>10 \%$ and $>20 \%$, respectively), for which systemic treatment is needed. ${ }^{8}$

\section{Co-morbidities in psoriasis}

There is evidence that the clinical impact of psoriasis is not limited to the skin. Arthritis is an established association of psoriasis. Psoriatic arthritis has been defined as an inflammatory arthritis occurring during the course of psoriasis and characterized by negative rheumatoid factor. ${ }^{3}$ In spite of the fact that psoriatic arthritis represents in clinical series a proportion as high as $25 \%$ of all psoriasis patients, population-based estimates suggest that no more than $4 \%$ to $5 \%$ of psoriatic patients presents seronegative arthritis as an associated feature. ${ }^{9}$

Psoriasis at its first clinical diagnosis has been associated with smoking and increased body mass index, ${ }^{10-12}$ and it is not surprising that established psoriasis has been associated with cardiovascular disease. ${ }^{13}$ Whether psoriasis is per se a risk factor for cardiovascular disease is still an open question.

Besides cardiovascular disease, a number of other conditions, most of which are also associated with smoking or obesity, have been linked with psoriasis, including inflammatory bowel disorders and tumors of specific sites, eg, lung cancer, colonic cancer, and kidney cancer. ${ }^{4}$ Not surprisingly, psoriasis has been also associated with depression. ${ }^{14}$

\section{Psoriasis causation}

While the exact cause remains unknown, it is clear that both genetic and environmental factors play a role (multifactorial inheritance). It has been estimated that the risk for a child to develop psoriasis is about $40 \%$ if both parents are affected and $15 \%$ if one parent or $6 \%$ if one sibling is affected. PSORS1 is the main psoriasis susceptibility gene which has been mapped in the major histocompatibility complex (MHC), ${ }^{15}$ a finding consistent with the notion that the pathogenesis of psoriasis involves antigen recognition by epidermal $\mathrm{CD}^{+} \mathrm{T}$ lymphocytes. Current genome-wide association studies using gene chips and adopting a casecontrol design instead of linkage analysis are fostering our understanding of genetic influences on psoriasis and confirm that psoriasis is a polygenic disorder to which relatively frequent alleles may contribute. Among the several genetic loci associated with psoriasis in case-control studies are IL12B, IL23R, IL23A. ${ }^{16,17}$ Observational studies have linked the onset of psoriasis with physical trauma, acute infection, some medications (eg, lithium salts and beta-blockers), stressful life events, cigarette smoking and increased body mass index. ${ }^{10-12}$ 


\section{Pathogenetic models: relevance of ThI and ThI 7 responses}

The hallmark features of a psoriatic plaque include hyperproliferation of epidermal keratinocytes with resulting hyperkeratosis, infiltration of lymphocytes, and angiogenesis. Mitotic activity of basal keratinocytes is increased several-fold in psoriatic skin, so that keratinocytes need only 3 to 5 days in order to move from basal layer to cornified layer instead of the normal 28 to 30 days. This dramatically shortened maturation time is accompanied by altered differentiation, reflected by the focal absence of the granular layer of the epidermis and parakeratosis, ie, presence of nuclei in the thickened cornified layer. The incompletely differentiated keratinocytes release few of the extracellular lipids used commonly in the adhesion of the keratinocytes, resulting in a poorly adherent stratum corneum. This is the basis for the formation of the classic silvery scale in the psoriatic lesions. What factors prompt localized hyperproliferation of keratinocytes and hyperkeratosis is still imprecisely understood. With the serendipitous discovery of the utility of cyclosporin in the treatment of psoriasis in 1979, the role of the immune system in triggering psoriasis has been increasingly emphasized. A vicious cycle of continuous $\mathrm{T}$ cell and dendritic cell (DC) activation can be envisioned within the chronic psoriatic plaque. During T-cell activation, the cytokine milieu determines the characteristics of the emerging effector $\mathrm{T}$ cells. In psoriasis, a so-called Th1 response seems to dominate, characterized by secretion, among others, of interferon (IFN)- $\gamma$, tumor necrosis factor (TNF)- $\alpha$, and interleukin (IL)-2. A more recent role for Th17 cells, independent of activation from IFN- $\gamma$, has been also proposed ${ }^{18}$ with an interplay between IFN- $\gamma$-producing Th1 cells and IL-17-producing T-cells in psoriatic lesions. ${ }^{19}$

A number of recent excellent reviews, to which the reader is addressed, thoroughly discuss current pathogenetic models..$^{20,21}$

\section{IL- I 2, IL-23 and Th I 7}

IL-23 p19 was discovered in $2000 .{ }^{22}$ It had no biological activity, but when combined with the IL-12p40 subunit of IL-12 formed a novel heterodimeric cytokine named IL-23. IL-23 was found to be expressed by several activated human cells like monocytes, macrophages, DCs, T cells, B cells and endothelial cells. ${ }^{22,23} \mathrm{IL}-23$ binds to its heterodimeric receptor complex composed of the IL-12R $\beta 1$ and IL-23R subunits. ${ }^{24}$ Whereas IL-12R $\beta 1$ is also part of the IL-12 receptor, IL-23R is unique to the IL-23 receptor complex (Figure 1). The IL-12R $\beta 1$ and

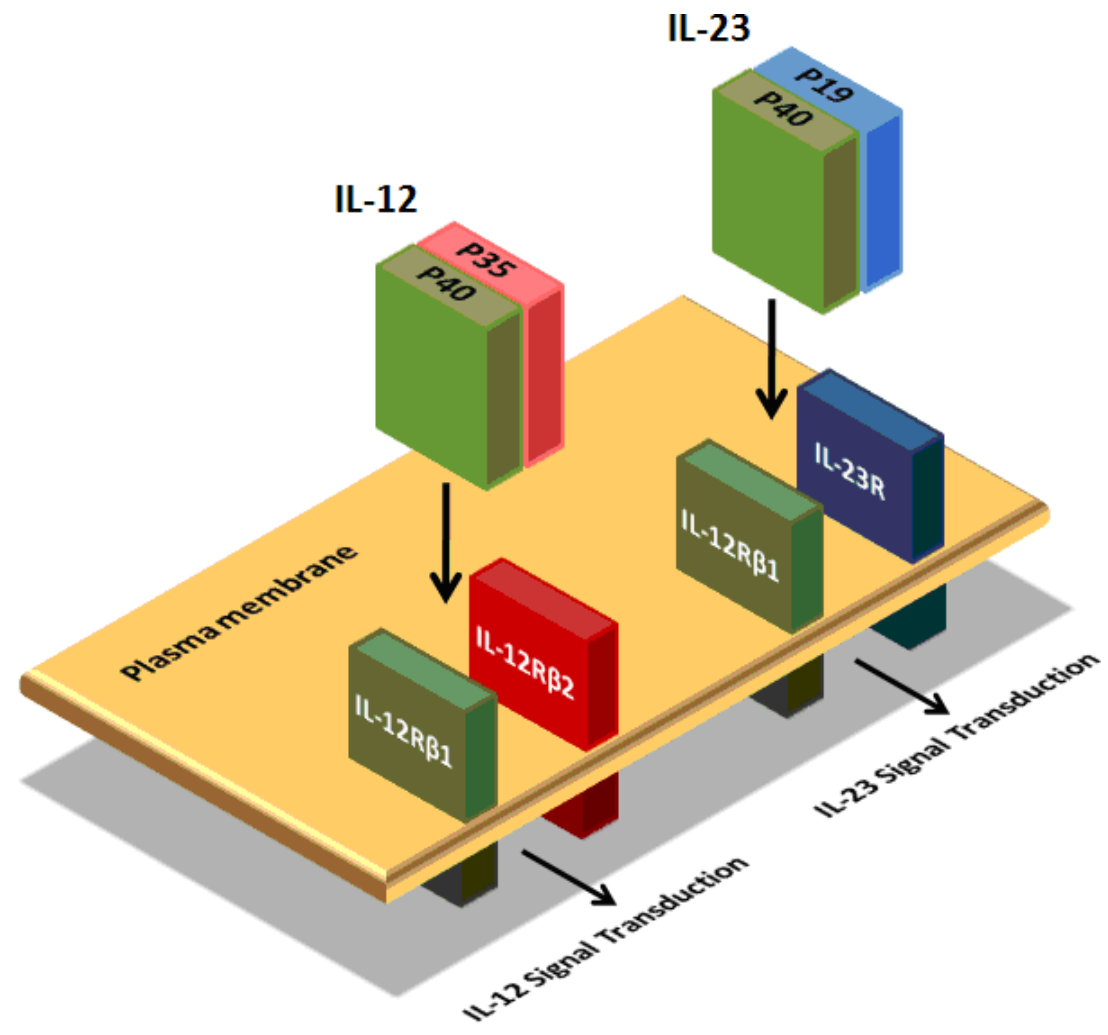

Figure I Schematic representation of interleukin (IL)- 12 and IL-23 with their receptors. 
IL-23R chain are associated with intracellular proteins of the Janus kinase (Jak) family to induce downstream signaling, resulting in a sequence of phosphorylation processes activating signal transducer and activator of transcription (STAT) molecules, namely STAT1, STAT3, STAT4, and STAT5, which translocate into the nucleus where they bind DNA in the promoter region of target genes. ${ }^{24}$

IL-23, rather than IL-12, appears to be the critical molecule for the development of autoimmune disease. Expression of IL-23p19 in lesional tissue in psoriasis, ${ }^{25}$ Crohn's disease ${ }^{26}$ and rheumatoid arthritis ${ }^{27}$ support this possible role.

While IL-12 causes CD4 ${ }^{+}$T-cell differentiation to IFN- $\gamma$ producing Th1 cells, IL-23 promotes the expansion of the Th17 population. In addition to IL-17A, these cells have been shown to produce IL-17F, IL-22 and IL-26, as well as IL-6, IL-21, TNF- $\alpha$-and IFN- $\gamma \cdot{ }^{28}$ To date, IL-17A, IL-17F and IL-26 are considered to be specific Th17 cytokines, whereas the others, can be produced also by Th1 cells. ${ }^{28}$ Functional studies of Th17 cytokines has revealed an important and unique role for these cytokines in host protection against infections with extracellular pathogens such as Gram-negative bacteria and Candida albicans. ${ }^{29}$ A number of autoimmune disorders have been associated with overproduction of Th17 cytokines and interference with their production attenuate autoimmune diseases. Interestingly, intradermal injection of IL-23 in mice led to erythema, induration and prominent dermal papillary blood vessels with histopathological features resembling psoriasis. ${ }^{30}$ IL-17 producing cells have been isolated from the dermis of psoriatic lesions. ${ }^{31}$ A key cytokine produced by Th17 cells is IL-22. IL-22 has a peculiar activity in immune innate response, and its role in the pathogenesis of psoriasis has been documented. ${ }^{32}$

\section{Existing therapeutic options for psoriasis}

The management of a chronic skin disorder like psoriasis is a multi-step process in which different phases can be identified. In particular, a clearance phase, which involves a more intensive treatment approach with the aim of clearing existing psoriasis lesions, and a maintenance phase, with the main aim of preventing disease relapse, are usually considered.

Treatment options for psoriasis are traditionally classified as topical, those based on ultraviolet light, and systemic, the last including conventional and so-called biological agents or biologics. ${ }^{33}$ The term biologics has been challenged. ${ }^{34}$ It refers to a heterogenous variety of antibodies and fusion proteins which directly target specific steps in the purported immunologic process of psoriasis. A classical approach to psoriasis treatment is stepwise, beginning with the least invasive and safest treatment, progressing to more potent, and potentially more risky, therapeutic options until sufficient psoriasis plaque clearance and control are achieved. According to this approach, topical preparations are the preferred option for mild disease. It has been documented that compliance may be quite poor with topical agents and treatment may be cumbersome. ${ }^{35}$ Treatment of moderate to severe psoriasis is often initiated with phototherapy or photochemotherapy. Phototherapy relies on ultraviolet $\mathrm{B}$ radiation (UVB) delivered as broadband, narrowband (restricted to the wavelength of 311 to $313 \mathrm{~nm}$ ) or as high-energy $308 \mathrm{~nm}$ monochromatic light through excimer laser. Photochemotherapy involves the combination of ultraviolet $\mathrm{A}$ radiation with psoralens (PUVA). Conventional systemic therapies currently approved in various countries for the treatment of moderate to severe psoriasis include ciclosporin, methotrexate, and oral retinoid therapy. Other systemic therapies, such as hydroxyurea or fumaric acid esters, are approved in a small number of countries or may be used off-label for the treatment of psoriasis. A better understanding of the immune pathways critical to the pathogenesis of psoriasis has prompted the development of new targeted agents, the so-called biologics. The biological agents available for treating psoriasis may be classified into two main categories: agents that modulate the function of $\mathrm{T}$ lymphocytes by acting on their receptors, namely alefacept and efalizumab (withdrawn from the market in 2009 because of the increased risk of progressive multifocal leukoencephalopathy), and cytokine-blocking agents. Before the introduction of IL-12/23 antagonists, the latter were limited to antagonists of TNF- $\alpha$ - etanercept, infliximab and adalimumab. Although biological treatments have been a significant advance in the management of psoriasis, their exact place in the hierarchy of systemic therapies will not be known until controlled trials have compared them against each other and with traditional approaches. The long-term safety of biologics is also a concern. TNF- $\alpha$ is produced by a wide range of immune and non-immune cells and has broad inflammatory effects, upregulating both innate and adaptive immunity. The use of TNF- $\alpha$ antagonists has been associated with an increased risk of tuberculosis reactivation ${ }^{36}$ and herpes zoster, ${ }^{37}$ and with case reports of severe opportunistic infections. ${ }^{38}$ Concerns have been also raised about an increased risk of solid tumors and lymphoma, ${ }^{39}$ but robust data are lacking. TNF- $\alpha$ antagonists can worsen pre-existing heart failure and should be avoided in severe congestive cardiac failure (New York Heart Association class III and IV) ${ }^{40}$ Cases of demyelinating 
disease have been reported with TNF- $\alpha$ antagonists, and it is recommended that these agents are avoided in patients with a personal or first-degree family history of demyelinating disorder. ${ }^{41}$ The formation of autoantibodies and of antibodies against biologic drugs themselves is sometimes observed but the clinical relevance is not yet clear. ${ }^{42}$

\section{Targeting IL-I 2 and IL-23 in psoriasis: ustekinumab}

As mentioned previously, IL-12 and IL-23 play key roles in the development of the immune response in psoriasis by inducing naive $\mathrm{CD}^{+}$lymphocytes to differentiate into Th1 and Th17 cells, respectively. In light of the biologic evidence available, the drug ustekinumab (formerly called CNTO 1275) was developed. This agent is a fully human IgG1 monoclonal antibody that binds to the p40 subunit of IL-12 and IL-23, and prevents their interaction with IL-12R $\beta 1$ thus blocking the cascade of cytokines associated with receptor activation. Ustekinumab is administered by subcutaneous injections. It has been approved for use in psoriasis, in Canada (December 2008), the European Union (January 2009), and the US (September 2009).

In addition to ustekinumab, another IL-12/23p40 monoclonal antibody is in an advanced phase of development, namely ABT-874. Finally, an oral IL-12/23 inhibitor has been tested in early clinical trials in Crohn's disease. ${ }^{43}$

\section{Pharmacokinetic studies}

The pharmacokinetic properties of ustekinumab have been well characterized following single-dose subcutaneous administration (0.27 to $2.7 \mathrm{mg} / \mathrm{kg}$ ) and single dose intravenous administration $(0.1$ to $5.0 \mathrm{mg} / \mathrm{kg})$ in patients with psoriasis. The pharmacokinetics of ustekinumab were linear over the wide dose range studied. After a single subcutaneous injection, ustekinumab showed to be slowly absorbed into systemic circulation, with a mean $\mathrm{T}_{\max }$ of approximately 12 days and then slowly eliminated from the circulation with a mean $\mathrm{t}_{1 / 2}$ of approximately 20 days. The mean $\mathrm{t}_{1 / 2}$, ranging from 14.9 to 28.6 days and increasing with increasing doses. $^{44}$

Population pharmacokinetic analyses have been also conducted based on data obtained from the large scale phase 3 studies PHOENIX 1 and PHOENIX 2, and with inclusion of serum concentration data from 1937 patients. ${ }^{45}$ Several variables, including demographics, baseline disease characteristics, prior use of systemic therapies for psoriasis, immune response status, and comorbidities, were evaluated. In the analyses, body weight, diabetes, and development of antibodies to ustekinumab, were important covariates significantly affecting the apparent clearance and/or apparent volume of distribution of ustekinumab. In particular, an approximately 55\% higher apparent clearance value and $37 \%$ higher volume of distribution was predicted for patients weighting more than $100 \mathrm{~kg}$ compared with those $100 \mathrm{~kg}$ or less. The mean steady state trough serum concentration with every 12-week dosing for patients weighing more than $100 \mathrm{~kg}$ was approximately 30\% lower than for patients weighing $100 \mathrm{~kg}$ or less. In patients with diabetes an approximately $28.7 \%$ higher apparent clearance value and $13.2 \%$ higher volume of distribution was predicted by the model. A total of 62 patients $(3.2 \%)$ developed antibodies against ustekinumab. These patients had an apparent clearance $35.5 \%$ higher than patients not developing antibodies. Only the effect of body weight was considered as clinically relevant.

\section{Drug-to-drug interaction}

In the context of the population pharmacokinetic study reference above, the potential effect on ustekinumab disposition of concomitant medications used by at least $5 \%$ of the study patients was assessed. ${ }^{46}$ None of the concomitant medications, including non-steroidal anti-inflammatory drugs (acetaminophen, ibuprofen, acetylsalicylic acid, and naproxen), oral hypoglycemic (metformin), dyslipidemics (atorvastatin), diuretics (hydrochlorothiazide), thyroid hormone (levothyroxine) and influenza vaccine, had a significant effect on the apparent clearance of ustekinumab.

\section{Pharmacodynamic studies}

Based on the same patient group assessed in the population pharmacokinetic studies mentioned above, exposure-response studies were performed, using serum ustekinumab concentrations, and reduction in PASI score as the response variable. ${ }^{47}$ The placebo effect although minor was also integrated into the model. The serum ustekinumab concentration causing $50 \%$ of the maximum effect $\left(\mathrm{IC}_{50}\right)$ showed a striking difference between partial responders, achieving PASI 50 but not PASI 75 at 28 weeks, and responders achieving PASI 75 at 28 weeks, the median $\mathrm{IC}_{50}$ value in partial responders being approximately 30 -fold higher than in responders. These data suggest that partial responders were not as sensitive as the responders to ustekinumab and that these patients may require higher doses and/or more frequent administrations to attain comparable efficacy. None of the covariates evaluated, including demographics, baseline disease characteristics, and co-morbidities, significantly contributed to the betweensubject variability in the pharmacodynamic parameters. 


\section{Pre-clinical and early clinical studies of ustekinumab in psoriasis}

Pre-clinical analyses in animal models have been conducted with anti-IL-12/23p40, showing that the antibodies can decrease disease activity in mouse models of multiple sclerosis $^{48}$ and Crohn's disease. ${ }^{49}$ Anti-IL-12/23p40 also successfully abolished psoriasis-like lesions in mice..$^{50}$

In humans, results from two phase 1 studies documented that ustekinumab acts via modulation of type- 1 chemokines and cytokines in lesional skin paralleled by a sustained clinical improvement following a single dose of the drug. ${ }^{44,51}$ Interestingly, after a single-dose administration, baseline levels of TNF- $\alpha$ were significantly correlated with clinical improvement at week 16, suggesting that the baseline levels of the cytokine may predict therapeutic response. ${ }^{52}$ In addition, gene expression analyses of pre- and posttreatment lesional skin indicate that the administration of anti-IL-12/23p40 rapidly by week 2 , downregulates mRNA expression of type 1 cytokines, as well as IL-12/23p40 and IL-23p19. IL-12p35 was upregulated, although IL-12p35 copy number was low and results were variable. The rapid decrease of IL-12/23p40 and IL-23p19 expression levels preceded clinical response and histological changes.

\section{Randomized clinical trials of ustekinumab in chronic plaque psoriasis}

Results from a total of four randomized clinical trials in chronic plaque psoriasis are available. ${ }^{53-56}$ These results are summarized in Table 1. In three studies ustekinumab was compared against placebo while in a single trial an active comparator, ie, etanercept, was adopted. In all the randomized trials available, disease severity was judged by assessing the extent and clinical aspects of psoriatic lesions at baseline by using the PASI score. Patients were eligible if their PASI score was $\geq 12$ or surface area involved was $\geq 10 \%$. Efficacy was primarily assessed by estimating the percentage of changes in the PASI score at 12 to 20 weeks compared with baseline (a variation of $75 \%$, referred to as PASI 75 , was considered as the main outcome). In spite of the use of placebo, no restriction in the eligibility criteria, based on the lack of previous response to other systemic agents, was made at entry. It should be noted that some complexities were added to the design of the studies with the combination of a first controlled study phase (main study phase) with a crossover phase where patients initially treated by placebo or etanercept were shifted to ustekinumab treatment (randomized to two different dosages in PHOENIX 1 and 2), and with a third randomized withdrawal study phase where treatment was withdrawn, in a randomized fashion, in patients who achieved a significant improvement on ustekinumab, and substituted by placebo (PHOENIX 1) or with an intensification phase where partial responders to ustekinumab were re-randomized to maintain their 12-week regimen or to escalate to dosing every 8 weeks (PHOENIX 2). The main problem originated by these sequential phases was that only a proportion of the patients initially randomized were actually evaluated in the subsequent phases.

Study NCT0032021653 is a phase II placebo-controlled trial involving 320 patients with moderate to severe plaque psoriasis. The main study phase lasted 20 weeks. The study design required patients in the ustekinumab group who did not respond $(\mathrm{PGA} \geq 3$ ) by week 16 to receive an additional dose, and those in the placebo group to receive a single dose of ustekinumab $90 \mathrm{mg}$ at week 20 . At week 12, 51.6\% and 59.4\% of patients who received ustekinumab $45 \mathrm{mg}$ and $90 \mathrm{mg}$ once weekly, respectively, and $67.2 \%$ and $81.3 \%$ who received four weekly 45-mg and 90-mg doses, respectively, achieved at least a $75 \%$ improvement from baseline in PASI (PASI $75)$, compared with $1.6 \%$ of patients who received placebo $(P<0.001$ each). Histological analyses were completed in the phase II study at baseline and week 12 . Ustekinumab significantly reduced the epidermal thickness of lesional skin.

The PHOENIX 1 trial was designed as a phase III study of the efficacy and safety of ustekinumab $45 \mathrm{mg}$ and $90 \mathrm{mg}$, administered subcutaneously. ${ }^{54}$ Participants were randomly assigned to receive ustekinumab 45 or $90 \mathrm{mg}$ subcutaneously at weeks 0 and 4 and then every 12 weeks, or placebo at weeks 0 and 4, with subsequent crossover to ustekinumab at week 12 . In addition, patients who were initially randomized to receive ustekinumab at week 0 and who achieved a significant improvement were re-randomized at week 40 to observe any loss of response with either maintenance therapy or treatment withdrawal for a total trial duration of 76 weeks. At week 12 , PASI 75, the primary end-point; was achieved by 171 (67.1\%) patients receiving ustekinumab $45 \mathrm{mg}, 170$ (66.4\%) receiving ustekinumab $90 \mathrm{mg}$, and eight (3.1\%) receiving placebo ( $P<0.0001$ for all the differences). Data concerning improvement of PASI of at least $90 \%$ (PASI 90) or of at least $50 \%$ (PASI 50), were consistent with those obtained for the primary end-point. Complete disappearance of psoriatic lesions (PASI 100) was achieved by 32 (12.5\%) patients receiving ustekinumab $45 \mathrm{mg}$, 28 (10.9\%) receiving ustekinumab $90 \mathrm{mg}$ and none of the patients receiving placebo. Clinical improvements were paralleled by improvements in the DLQI. At week 40, long-term response had been achieved by 150 patients in the $45 \mathrm{mg}$ ustekinumab group and 172 patients in the $90 \mathrm{mg}$ group. Of these, 162 patients were randomly assigned to 
Table I Summary of clinical data from phase III randomized trials of ustekinumab in chronic plaque psoriasis

\begin{tabular}{|c|c|c|c|}
\hline Trial & No. patients recruited & Efficacy data & Safety data \\
\hline NCT00320216 & 320 & $\begin{array}{l}\text { PASI } 75 \text { at week } 20 \text { (primary end point): } \\
\text { Ustekinumab: } \\
45 \mathrm{mg} \text { once weekly: } 52 \% \\
90 \mathrm{mg} \text { once weekly: } 59 \% \\
45 \mathrm{mg} 4 \text { times weekly: } 67 \% \\
90 \mathrm{mg} 4 \text { times weekly: } 81 \%\end{array}$ & $\begin{array}{l}\text { Any adverse event: } \\
\text { Ustekinumab: } 68 \%-90 \% \text { according to dosage } \\
\text { Placebo: } 72 \% \\
\text { Serious adverse events: } \\
\text { Ustekinumab: } 2 \%-5 \% \text {, according to dosage }\end{array}$ \\
\hline & & Placebo: $2 \%$ & Placebo: $1 \%$ \\
\hline PHOENIXI & 766 & 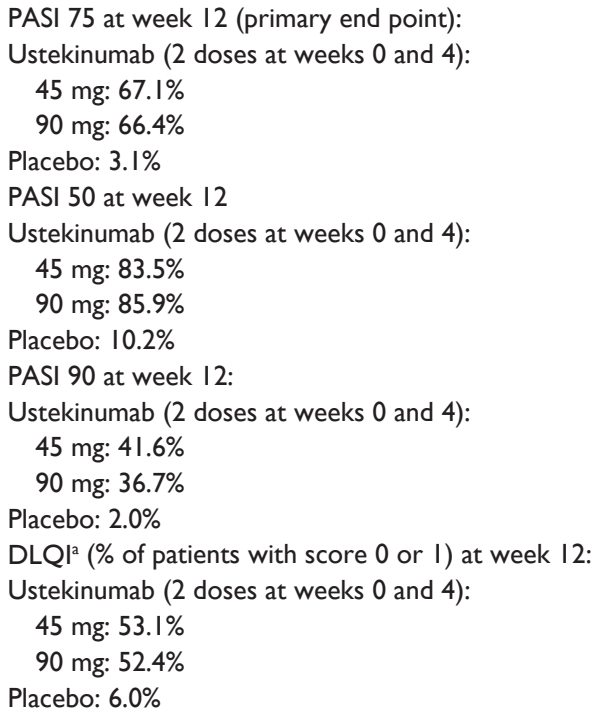 & $\begin{array}{l}\text { Any adverse event: } \\
\text { Ustekinumab: } 57.6 \% \text { and } 5 \mathrm{I} .4 \% \text { of patients on } \\
45 \mathrm{mg} \text { and } 90 \mathrm{mg} \text {, respectively } \\
\text { Placebo: } 48.2 \% \\
\text { (most common events: upper respiratory } \\
\text { tract infection, arthralgia, and headache) } \\
\text { Serious adverse events: } \\
\text { Ustekinumab: } 0.8 \% \text { and } 1.6 \% \text { of patients on } \\
45 \mathrm{mg} \text { and } 90 \mathrm{mg} \text {, respectively } \\
\text { Placebo: } 0.8 \% \\
\text { (most common serious } \\
\text { events: infections) }\end{array}$ \\
\hline PHOENIX2 & 1230 & $\begin{array}{l}\text { PASI } 75 \text { at week I } 2 \text { (primary end point) } \\
\text { Ustekinumab (2 doses at weeks } 0 \text { and } 4) \text { : } \\
45 \text { mg: } 66.7 \% \\
90 \mathrm{mg}: 75.7 \% \\
\text { Placebo: } 3.7 \% \\
\text { PASI } 50 \text { at week } 12 \\
\text { Ustekinumab (2 doses at weeks } 0 \text { and } 4) \text { : } \\
45 \mathrm{mg:} 83.6 \% \\
90 \mathrm{mg}: 89.3 \% \\
\text { Placebo: } 10 \% \\
\text { PASI } 90 \text { at week } 12 \\
\text { Ustekinumab (2 doses at weeks } 0 \text { and } 4) \text { : } \\
45 \mathrm{mg}: 42.3 \% \\
90 \mathrm{mg}: 50.9 \% \\
\text { Placebo: } 0.7 \% \\
\text { DLQI (\% of patients with score } 0 \text { or I) } \\
\text { at week } 12(*): \\
\text { Ustekinumab: } \\
45 \mathrm{mg}: 55.3 \% \\
90 \mathrm{mg}: 56.4 \% \\
\text { Placebo: } 3.2 \%\end{array}$ & $\begin{array}{l}\text { Any adverse event: } \\
\text { Ustekinumab: } 53.1 \% \text { and } 47.9 \% \text { of patients on } \\
45 \mathrm{mg} \text { and } 90 \mathrm{mg} \text {, respectively } \\
\text { Placebo: } 49.8 \% \\
\text { (most common events: arthralgia, cough, } \\
\text { headache, upper respiratory tract infection, } \\
\text { and injection site erythema) } \\
\text { Serious adverse events: } \\
\text { Ustekinumab: } 2.0 \% \text { and } \\
\text { I.2\% of patients on } 45 \mathrm{mg} \text { and } 90 \mathrm{mg} \text {, } \\
\text { respectively } \\
\text { Placebo: } 2.0 \% \\
\text { (most common serious events: infections) }\end{array}$ \\
\hline ACCEPT & 903 & $\begin{array}{l}\text { PASI } 75 \text { at week I } 2 \text { (primary end point): } \\
\text { Ustekinumab ( } 2 \text { doses at week } 0 \text { and } 4): \\
45 \mathrm{mg:} 67.5 \% \\
90 \mathrm{mg}: 73.8 \% \\
\text { Etanercept ( } 50 \mathrm{mg} \text { twice weekly): } \\
56.8 \% \\
\text { PASI } 90 \text { at week I } 2 \\
\text { Ustekinumab ( } 2 \text { doses at weeks } 0 \text { and } 4) \text { : } \\
45 \mathrm{mg}: 36.4 \% \\
90 \mathrm{mg}: 44.7 \% \\
\text { Etanercept (50 mg twice weekly): } \\
23.1 \%\end{array}$ & $\begin{array}{l}\text { Any adverse event: } \\
\text { Ustekinumab: } 66 \% \text { and } 69.2 \% \text { of patients } \\
\text { on } 45 \mathrm{mg} \text { and } 90 \mathrm{mg} \text {, respectively } \\
\text { Etanercept: } 70 \% \\
\text { (most common events: upper respiratory tract } \\
\text { infection, headache, back pain, injection-site } \\
\text { reaction) } \\
\text { Serious adverse events: } \\
\text { Ustekinumab: } 1.9 \% \text { and } 1.2 \% \text { of patients on } \\
45 \mathrm{mg} \text { and } 90 \mathrm{mg} \text {, respectively } \\
\text { Etanercept: } 1.2 \% \\
\text { (most common serious events: infections) }\end{array}$ \\
\hline
\end{tabular}

Abbreviation: PASI, psoriasis area and severity index.

aDLQI is a I0-item questionnaire that determines the extent of the effect of psoriasis on patient-reported quality of life, with overall scores ranging from 0 ("not at all") to 30 ("very much"). 
maintenance ustekinumab and 160 to withdrawal. PASI 75 response was better maintained to at least 1 year in those receiving maintenance ustekinumab than in those withdrawn from treatment at week 40.

The aim of the PHOENIX 2 phase III trial was to assess whether dosing intensification would increase the response to the treatment in partial responder patients (between PASI 50 and PASI 75). ${ }^{55}$ Subjects were randomly assigned to receive ustekinumab 45 or $90 \mathrm{mg}$ subcutaneously at weeks 0 and 4 and then subsequently every 12 weeks, or to receive placebo at weeks 0 and 4, with subsequent crossover to the study drug at week 12. Partial responders among those originally randomized to ustekinumab, were re-randomized at week 28 to receive the drug every 12 weeks or to increase dose administration to every 8 weeks for a total trial duration of 52 weeks. At week 12, PASI 75, the primary end-point, was achieved by $273(66.7 \%)$ patients receiving ustekinumab $45 \mathrm{mg}, 311$ (75.7\%) receiving ustekinumab $90 \mathrm{mg}$, and 15 (3.7\%) receiving placebo. Complete clearance was achieved by 74 (18.1\%) patients receiving ustekinumab $45 \mathrm{mg}, 75$ (18.2\%) receiving ustekinumab $90 \mathrm{mg}$, and none of the patients receiving placebo. About $20 \%$ of the patients treated by ustekinumab were classified as partial responders. In the group on ustekinumab $90 \mathrm{mg}$, PASI 75 at week 52, was achieved by 22 (68.8\%) out of 32 patients randomized to receive an intensified regimen with ustekinumab $90 \mathrm{mg}$ every 8 weeks, and 11 (33.3\%) out of 33 patients who continued to receive the same dose every 12 weeks $(P=0.004)$. No similar improved response was observed with dose intensification in patients on ustekinumab $45 \mathrm{mg}$. Partial responders appeared to represent a distinct subgroup of patients who had higher bodyweight, a longer duration of skin disease, a history of psoriatic arthritis and an overall greater resistance to biological agents compared with responders. Although this subpopulation had lower mean serum drug levels of ustekinumab than did patients who responded to treatment, lower serum concentrations of ustekinumab alone did not completely explain their partial response. The response to dose intensification in the $90 \mathrm{mg}$ but not the $45 \mathrm{mg}$ ustekinumab groups suggests that these patients may need for response a serum concentration of the drug four to five times higher compared with responders.

The ACCEPT trial was a 12-week trial comparing ustekinumab $40 \mathrm{mg}$ or $90 \mathrm{mg}$ at week 0 and 4 with subcutaneous etanercept, $50 \mathrm{mg}$, twice-weekly for 12 weeks. ${ }^{56}$ Patients in the etanercept group who did not have a response (ie, patients classified as having moderate, marked, or severe psoriasis) at week 12 received $90 \mathrm{mg}$ of ustekinumab at weeks 16 and 20 , and patients who did not have a response to ustekinumab received one additional dose of ustekinumab at week 16 . Treatment was interrupted starting at week 12 in all patients with cleared, minimal, or mild psoriasis. Patients were retreated with ustekinumab if psoriasis recurred and were followed up to week 44. At week 12, a total of $67.5 \%$ of patients who received $45 \mathrm{mg}$ of ustekinumab and $73.8 \%$ of patients who received $90 \mathrm{mg}$ of ustekinumab achieved PASI 75, as compared with $56.8 \%$ of those who received high dose etanercept $(P=0.01$ and $P<0.001$, respectively). At week 12 , clearance was documented in $16.3 \%$ of patients on ustekinumab $45 \mathrm{mg}, 26.2 \%$ on ustekinumab $90 \mathrm{mg}$, and $8.6 \%$ on etanercept $(P=0.006$ and $P<0.001$, respectively). Among patients who did not respond to etanercept, $48.9 \%$ had at least $75 \%$ improvement in the PASI score and $23.4 \%$ had at least a $90 \%$ improvement after crossing over to $90 \mathrm{mg}$ of ustekinumab for 12 weeks. The median time to recurrence was 14.4 weeks among patients who received $45 \mathrm{mg}$ of ustekinumab, 18.1 weeks among those who received $90 \mathrm{mg}$ of ustekinumab, and 7.3 weeks among those who received etanercept. Of the 633 patients who were treated with ustekinumab again after the recurrence of psoriasis, 534 (84.4\%) had a physician's global assessment score of 0 to 2 within 12 weeks after retreatment.

Ustekinumab has been also studied in psoriatic arthritis. A crossover, phase II study included 76 patients injected with this drug at weeks $0,1,2$ and 3 , who then received placebo injections at weeks 12 and 16. Seventy other patients received placebo at $0,1,2$ and 3 weeks, followed by ustekinumab injections at weeks 12 and 16. At week 12, 42\% of the treatment group achieved an ACR20 (20\% improvement in symptoms according to the American College of Rheumatology criteria) compared with $14 \%$ of the placebo group. By the end of the 36 -week study period, $42 \%$ of the original placebo patients who had received injections of ustekinumab only at weeks 12 and 16 achieved an ACR20 response. ${ }^{57}$ These results are promising, but further data possibly against an active comparator and on a longer term run are required in psoriatic arthritis.

\section{Safety issues}

The current understanding of the safety of ustekinumab in psoriasis is mainly derived from a total of 2266 patients treated in the context of controlled randomized trials and their subsequent open phase for up to 18 months. ${ }^{58}$ During the placebo-controlled phases of the trials, the rates and types of adverse events, as well as laboratory abnormalities, were similar among the patients receiving placebo and ustekinumab (50.4\% vs $54.6 \%$, respectively). The incidence of serious infections with ustekinumab $45 \mathrm{mg}$ and $90 \mathrm{mg}$ was 1.2 and 1.7 per 100 patient-years of follow-up, respectively, and 
malignancies other than nonmelanoma skin cancer (NMSC), 0.25 and 0.57 per 100 patient-years, respectively. These rates were comparable with placebo-treated patients. In spite of these reassuring data, long-term effects and safety profile remain in question as for any newly developed medication, and post-marketing data are still required for ustekinumab especially to assess the risk for rare but clinically relevant conditions and for events with a latency period (Table 2).

One concern is the potential carcinogenicity risk associated with ustekinumab, since rodent tumor models suggest that mouse IL-12 can promote antitumor effects and that IL-12/ 23p40-deficient mice, or mice treated with anti-IL-12/23p40 antibody, have decreased host defense to tumors and increased risk of ultraviolet-induced skin tumors. ${ }^{59}$ On the other hand, IL-23p19-deficient mice have a strong resistance to tumor challenge. ${ }^{60}$ The relevance of these findings for malignancy risk in humans treated by ustekinumab is unknown.

Another concern is a possible increased risk of infections in patients treated with anti-IL-12/23p40 antibodies. Data from studies in deficient knockout mice or in mice following very high doses of neutralizing antibody administration suggest that IL-12 (Th1) and IL-23 (Th17) responses may contribute to protective immune responses to viral and bacterial pathogens. ${ }^{61,62}$ In contrast to observations in murine models, humans with genetic deficiencies in the Th1 and Th17 pathways, involving, among the others, IL-12/23p40, IL-12R $\beta 1$, IFN- $\gamma$ receptor 1 and 2 , have normal resistance to viral or fungal infections ${ }^{63,64}$ but are susceptible to non-tuberculosis primary Mycobacterium and recurring Salmonella spp. infections. To date, no cases of typical or atypical mycobacterial or salmonella infections have been reported in clinical studies of ustekinumab. Reasons may be

Table 2 Main safety concerns in ustekinumab-treated patients

\begin{tabular}{ll}
\hline Safety issue & Evidence available \\
\hline Severe infections & $\begin{array}{l}\text { Humans with genetic deficiencies in } \\
\text { IL-I2/23p40, IL-I2R } \beta \text { I, IFN- } \gamma \text { receptor I and 2, } \\
\text { are especially susceptible to non- } \\
\text { tuberculosis primary Mycobacterium and } \\
\text { recurring Salmonella spp. infections } \\
\text { IL-I2/23p40-deficient mice have decreased } \\
\text { host defense to tumors and increased risk } \\
\text { of ultraviolet-induced skin tumors } \\
\text { One case has been reported on } \\
\text { Reversible posterior } \\
\text { leukoencephalopathy }{ }^{\mathrm{a}}\end{array} \quad \begin{array}{l}\text { ustekinumab treatment. It has been } \\
\text { described in immune-suppressed patients }\end{array}$ \\
\hline
\end{tabular}

${ }^{a}$ A syndrome characterized by headache, confusion, seizures, visual loss. It has been associated with malignant hypertension, eclampsia and immune-suppressive treatment in the post-transplant setting. Symptoms usually abate with responsible drug dose reduction, or control of hypertension and electrolyte level. represented by screening for latent tuberculosis at baseline and treatment of positive cases, or by limited exposure to date in large endemic populations. It is also possible that ustekinumab treatment does not confer complete inhibition of IL-12/23p40, as is observed with genetic deficiencies.

Further data are also required to assess the effectiveness of ustekinumab compared with other more commonly used agents, and to explore the use of the drug in varieties of psoriasis other than chronic plaque. Psoriasis is associated with several co-morbidities, and one should consider whether aggressive management of psoriasis, especially with a systemic agent such as ustekinumab, could change the course of these co-morbidities.

Because of concerns over potential long-term risks, the Food and Drug Administration is requiring a risk evaluation and mitigation strategy that include a 5-year follow-up of patients originally recruited into clinical trials, the enrollment of newly treated patients in a registry that will follow them up for 8 years, and the establishment of a pregnancy registry. The Psoriasis Longitudinal Assessment and Regstry (PSOLAR) is a Centocor Ortho Biotech Inc. sponsored, voluntary registry, originally implemented for the postmarketing evaluation of infliximab, which is now available in several countries to collect information on patients treated with ustekinumab and other systemic agents for psoriasis (http://clinicaltrials.gov/ct2/show/NCT00508547).

\section{Treatment guidelines}

Ustekinumab is administered by subcutaneous injection. For patients weighing $<100 \mathrm{~kg}$, the dose is $45 \mathrm{mg}$ initially and 4 weeks later, followed by $45 \mathrm{mg}$ every 12 weeks. For patients weighing $>100 \mathrm{~kg}$, the recommended dose is $90 \mathrm{mg}$ initially and 4 weeks later, followed by $90 \mathrm{mg}$ every 12 weeks. In Europe, ustekinumab has been approved by the EMEA, as for other biological agents, for the treatment of severe plaque psoriasis in adults who fail to respond to or who have contraindications to, or are intolerant to other systemic agents, including cyclosporin, methotrexate, and PUVA. Similar criteria were adopted for registration in Canada, while in the US no restriction was made based on previous treatment response. As a consequence, patients exposed to ustekinumab in Europe and Canada are likely to be more complex than those enrolled in US and they need more strict monitoring.

Ustekinumab was not included in the recently delivered European S-3 guidelines for the treatment of psoriasis, because the deadline of the literature search was prior to the registration of ustekinumab. ${ }^{65}$ The guidelines of the 
British Association of Dermatologists restrict the use to ustekinumab to patients who fulfil the EMEA registration criteria and where TNF antagonist therapy has failed or was contraindicated. ${ }^{66}$

\section{Concluding remarks}

Given the currently known characteristics of ustekinumab, the drug appears to be an effective, relatively safe and convenient agent in treating psoriasis. However, wider experience is needed. Both pragmatic randomized clinical trials adopting an active comparator and formal cohort studies possibly nested within disease registries are needed to better define the activity profile of the drug and to better establish its role in the clinical management of psoriasis.

\section{Disclosures}

The authors declare no conflicts of interest.

\section{References}

1. Jobling R, Naldi L. Assessing the impact of psoriasis and the relevance of qualitative research. J Invest Dermatol. 2006;126:1438-1440.

2. Nijsten T, Wakkee M. Complexities of the association between psoriasis and comorbidities. J Invest Dermatol. 2009;129:1601-1163.

3. Helliwell PS, Taylor WJ. Classification and diagnostic criteria for psoriatic arthritis. Ann Rheum Dis. 2005;64 Suppl 2:ii3-ii8.

4. Naldi L. Epidemiology of psoriasis. Curr Drug Targets Inflamm Allergy. 2004;3:121-128.

5. Naldi L, Minelli C. Dermatology. In: Machin D, Day S, Green S, editors. Textbook of Clinical Trials. Chichester, UK: John Wiley \& Sons, Ltd; 2006. p. 263-285.

6. Schmid-Ott G, Schallmayer S, Calliess IT. Quality of life in patients with psoriasis and psoriasis arthritis with a special focus on stigmatization experience. Clin Dermatol. 2007;25:547-554.

7. Schmitt J, Wozel G. The psoriasis area and severity index is the adequate criterion to define severity in chronic plaque-type psoriasis. Dermatology. 2005;210:194-199.

8. EMEA Committee for Proprietary Medical Products. Note for guidance on clinical investtigation of medical products indicated for the treatment of psoriasis. CPMP/EWP 2454/02.

9. Silman AJ, Hochberg MC. Psoriatic arthropathy. In: Epidemiology of the rheumatic diseases. New York: Oxford University Press; 1993:86-104.

10. Naldi L, Chatenoud L, Linder D, Belloni Fortina A, Peserico A, Virgili AR, et al. Cigarette smoking, body mass index, and stressful life events as risk factors for psoriasis: results from an Italian case-control study. J Invest Dermatol. 2005;125:61-67.

11. Setty AR, Curhan G, Choi HK. Obesity, waist circumference, weight change, and the risk of psoriasis in women: Nurses' Health Study II. Arch Intern Med. 2007;167:1670-1675.

12. Setty AR, Curhan G, Choi HK. Smoking and the risk of psoriasis in women: Nurses' Health Study II. Am J Med. 2007;120:953-959.

13. Gelfand JM, Troxel AB, Lewis JD, et al. The risk of mortality in patients with psoriasis: results from a population-based study. Arch Dermatol. 2007;143:1493-1499.

14. Kimball AB, Jacobson C, Weiss S, Vreeland MG, Wu Y. The psychosocial burden of psoriasis. Am J Clin Dermatol. 2005;6:383-392.

15. Nair RP, Stuart PE, Nistor I, Hiremagalore R, Chia NV, Jenisch S, et al. Sequence and haplotype analysis supports HLA-C as the psoriasis susceptibility 1 gene. Am J Hum Genet. 2006;78:827-851.
16. Nair R, Duffin KC, Helms C, Ding J, Stuart PE, Goldgar D, et al. Genome-wide scan reveals association of psoriasis with IL-23 and NF-kB pathways. Nat Genet. 2009;41:199-204.

17. Nair RP, Ruether A, Stuart PE, Jenisch S, Tejasvi T, Hiremagalore R, et al. Polymorphisms of the IL12B and IL23R genes are associated with psoriasis. J Invest Dermatol. 2008;128:1653-1661.

18. Blauvelt A. T-helper 17 cells in psoriatic plaques and additional genetic links between IL-23 and psoriasis. J Invest Dermatol. 2008;128:1064-1067.

19. Kryczek I, Bruce AT, Gudjonsson JE, Johnston A, Vatan L, Szeliga W, et al. Induction of memory IL- $17^{+} \mathrm{T}$ cell trafficking and expansion by IFN-gamma: Mechanism and pathological relevance. J Immunol. 2008;181:4733-4741.

20. Nestle FO, Kaplan DH, Barker JN. Psoriasis. $N$ Engl J Med. 2009;361:496-509.

21. Di Cesare A, Di Meglio P, Nestle FO. The IL-23/Th17 axis in the immunopathogenesis of psoriasis. J Invest Dermatol. 2009;129: 1339-1350.

22. Oppmann B, Lesley R, Blom B, Timans JC, Xu Y, Hunte B, et al. Novel p19 protein engages IL-12p40 to form a cytokine, IL-23, with biological activities similar as well as distinct from IL-12. Immunity. 2000;13:715-725.

23. Pirhonen J, Matikainen S, Julkunen I. Regulation of virus-induced IL-12 and IL-23 expression in human macrophages. J Immunol. 2002;169:5673-5678.

24. Parham C, Chirica M, Timans J, Vaisberg E, Travis M, Cheung J, et al. A receptor for the heterodimeric cytokine IL-23 is composed of IL-12Rbeta1 and a novel cytokine receptor subunit, IL-23R. J Immunol. 2002;168:5699-5708.

25. Lee J, Trepicchio WL, Oestreicher JL, Pittman D, Wang F, Chamian F, et al. Increased expression of interleukin 23 p19 and p40 in lesional skin of patients with psoriasis vulgaris. Exp Med. 2004;199:125-130.

26. Schmidt C, Giese T, Ludwig B, Mueller-Molaian I, Marth T, Zeuzem S, et al. Expression of interleukin-12-related cytokine transcripts in inflammatory bowel disease: elevated interleukin-23p19 and interleukin$27 \mathrm{p} 28$ in Crohn's disease but not in ulcerative colitis. Inflamm Bowel Dis. 2005;11:16-23.

27. Sato K, Suematsu A, Okamoto K, Yamaguchi A, Morishita Y, Kadono $\mathrm{Y}$, et al. Th17 functions as an osteoclastogenic helper $\mathrm{T}$ cell subset that links T cell activation and bone destruction. J Exp Med. 2006; 203:2673-2682.

28. Volpe E, Servant N, Zollinger R, Bogiatzi SI, Hupe P, Barillot E, et al. A critical function for transforming growth factor-beta, interleukin-23 and proinflammatory cytokines in driving and modulating human T(H)-17 responses. Nat Immunol. 2008;9:650-657.

29. Huang W, Na L, Fidel PL, Schwarzenberger P. Requirement of interleukin-17A for systemic anti-Candida albicans host defense in mice. J Infect Dis. 2004;190:624-631.

30. Chan JR, Blumenschein W, Murphy E, Diveu C, Wiekowski M, Abbondanzo S, et al. IL-23 stimulates epidermal hyperplasia via TNF and IL-20R2-dependent mechanisms with implications for psoriasis pathogenesis. J Exp Med. 2006;203:2557-2587.

31. Lowes MA, Kikuchi T, Fuentes-Duculan J, Cardinale I, Zaba LC, Haider AS, et al. Psoriasis vulgaris lesions contain discrete populations of Th1 and Th17 T cells. J Invest Dermatol. 2008;128:1207-1211.

32. Wolk K, Witte E, Wallace E, Docke WD, Kunz S, Asadullah K, et al. IL-22 regulates the expression of genes responsible for antimicrobial defense, cellular differentiation, and mobility in keratinocytes: a potential role in psoriasis. Eur J Immunol. 2006;36:1309-1323.

33. Naldi L, Rzany B. Chronic plaque psoriasis. Clin Evid. 2009;pii:1706.

34. Katz KA. "Biologics": a clinically meaningless term. Br J Dermatol. 2006;154:809-812.

35. Van de Kerkhof PCM, De Hoop D, De Korte J, Cobelens SA, Kuipers MV. Patient Compliance and disease management in the treatment of psoriasis in the Netherlands. Dermatology. 2000;200: 292-298. 
36. Cagatay T, Aydın M, Sunmez S, Cagatay P, Gulbaran Z, Gul A, et al. Follow-up results of 702 patients receiving tumor necrosis factor-alpha antagonists and evaluation of risk of tuberculosis. Rheumatol Int. 2009 Oct 21. [Epub ahead of print].

37. Kim SY, Solomon DH. Tumor necrosis factor blockade and the risk of viral infection. Nat Rev Rheumatol. 2010 Feb 9. [Epub ahead of print].

38. Kamili QA, Menter A. Atypical presentation of histoplasmosis in a patient with psoriasis and psoriatic arthritis on infliximab therapy. J Drugs Dermatol. 2010;9:57-60.

39. Wolfe F, Michaud K. Biologic treatment of rheumatoid arthritis and the risk of malignancy: analyses of a large US observational study. Arthritis Rheum. 2007;56:2886-2895.

40. Kwon HJ, Coté TR, Cuffe MS, et al. Case reports of heart failure after therapy with a tumor necrosis factor antagonist. Ann Intern Med. 2003;138:807-811.

41. Mohan N, Edwards ET, Cupps TR, et al. Demyelination occurring during anti-tumor necrosis factor alpha therapy for inflammatory arthritides. Arthritis Rheum. 2001;44:2862-2869.

42. Williams EL, Gadola S, Edwards CJ. Anti-TNF-induced lupus. Rheumatology (Oxford). 2009;48:716-720.

43. Burakoff R, Barish CF, Riff D, Pruitt R, Chey WY, Farraye FA, et al. A phase $1 / 2 \mathrm{~A}$ trial of STA 5326, an oral interleukin-12/23 inhibitor, in patients with active moderate to severe Crohn's disease. Inflamm Bowel Dis. 2006;12:558-565.

44. Gottlieb AB, Cooper KD, McCormick TS, Toichi E, Everitt DE, Frederick B, et al. A phase I, double-blind, placebo-controlled study evaluating single subcutaneous administrations of a human interleukin$12 / 23$ monoclonal antibody in subjects with plaque psoriasis. Curr Med Res Opin. 2007;23:1081-1092.

45. Zhu Y, Hu C, Lu M, Liao S, Marini JC, Yohrling J, et al. Population pharmacokinetic modelling of ustekinumab, a human monoclonal antibody targeting IL-12/23p40, in patients with moderate-to-severe plaque psoriasis. J Clin Pharmacol. 2009;49:162-175.

46. Zhou H, Davis H M. Risk-based strategy for the assessment of pharmacokinetic drug-drug interactions for therapeutic monoclonal antibodies. Drug Discov Today. 2009;14:891-898.

47. Zhou H, Hu C, Zhu Y, Lu M, Liao S, Yeilding N, Davis HM. Population-based exposure-efficacy modeling of ustekinumab in patients with moderate to severe plaque psoriasis. J Clin Pharmacol. 2010;50:257-267.

48. Leonard JP, Waldburger KE, Schaub RG, Smith T, Hewson AK, Cuzner ML, et al. Regulation of the inflammatory response in animal models of multiple sclerosis by interleukin-12. Crit Rev Immunol. 1997; 17:545-553.

49. Neurath MF, Fuss I, Kelsall BL, Stuber E, Strober W. Antibodies to interleukin 12 abrogate established experimental colitis in mice. $J$ Exp Med. 1995;182:1281-1290.

50. Ma HL, Liang S, Li J, Napierata L, Brown T, Benoit S, et al. IL-22 is required for Th17 cellmediated pathology in a mouse model of psoriasislike skin inflammation. J Clin Invest. 2008;118:597-607.

51. Kauffman CL, Aria N, Toichi E, McCormick TE, Cooper KD, Gottlieb AB, et al. A phase I study evaluating the safety, pharmacokinetics, and clinical response of a human IL-12 p40 antibody in subjects with plaque psoriasis. J Invest Dermatol. 2004;123:1037-1044
52. Toichi E, Torres G, McCormick TS, Chang T, Mascelli MA, Kauffman CL, et al. An anti-IL-12p40 antibody down-regulates type 1 cytokines, chemokines, and IL-12/IL-23 in psoriasis. J Immunol. 2006; 177:4917-4926.

53. Krueger GG, Langley RG, Leonardi C, Yeilding N, Guzzo C, Wang Y, et al. CNTO 1275 Psoriasis Study Group, A human interleukin-12/23 monoclonal antibody for the treatment of plaque psoriasis. $N$ Eng $J$ Med. 2007;356:580-592.

54. Leonardi CL CL, Kimball AB, Papp KA, Yeilding N, Guzzo C, Wang Y, et al. Efficacy and safety of ustekinumab, a human interleukin-12/23 monoclonal antibody, in patients with psoriasis: 76-week results from a randomised, double-blind, placebo-controlled trial (PHOENIX1). Lancet. 2008;371:1665-1674.

55. Papp AK, Langley RG, Lebwohl M, Krueger GG, Szapary P, Yeilding N, et al. Efficacy and safety of ustekinumab, a human interleukin-12/23 monoclonal antibody, in patients with psoriasis: 52-week results from a randomised, double-blind, placebo-controlled trial (PHOENIX2). Lancet. 2008;371:1675-1684.

56. Griffiths CE, Strober BE, van de Kerkhof P, Ho V, Fidelus-Gort R, Yeilding N, et al. Comparison of ustekinumab and etanercept for moderate-to-severe psoriasis. $N$ Engl J Med. 2010;362:118-128.

57. Gottlieb A, Menter A, Mendelsohn A, et al. Ustekinumab, a human interleukin 12/23 monoclonal antibody, for psoriatic arthritis: randomized, double-blind, placebo controlled, crossover trial. Lancet. 2009;373:605-606.

58. Elliott M, Benson J, Blank M, et al. Ustekinumab: lessons learned from targeting Interlukin-12/23p40 in immune-mediated diseases. Ann NY Acad Sci. 2009;1182:97-110.

59. Meeran SM, Mantena SK, Meleth S, Elmets CA, Katiyar SK. Interleukin-12- deficient mice are at greater risk of UV radiationinduced skin tumors and malignant transformation of papillomas to carcinomas. Mol Cancer Ther. 2006;5:825-832.

60. Langowski JL, Zhang X, Wu L, Basham B, McClanahan T, Kastelein RA, Oft M. IL-23 promotes tumor incidence and growth. Nature. 2006;442:461-465.

61. Holscher C, Atkinson RA, Arendse B, Brown N, Myburgh E, Alber G, et al. A protective and agonistic function of IL-12p40 in mycobacterial infection. J Immunol. 2001;167:6957-6966.

62. Wang Y, Chaudhri G, Jackson RJ, Karupiah G. IL-12p40 and IL-18 play pivotal roles in orchestrating the cell-mediated immune response to a poxvirus infection. $J$ Immunol. 2009;183:3324-3331.

63. Altare F, Durandy A, Lammas D, Emile JF, Lamhamedi S, Le Deist F, et al. Impairment of mycobacterial immunity in human interleukin-12 receptor deficiency. Science. 1998;280:1432-1435.

64. de Jong R, Altare F, Haagen IA, Elferink DG, Boer T, van Breda Vriesman PJ, et al. Severe mycobacterial and Salmonella infections in interleukin-12 receptor-deficient patients. Science. 1998;280:1435-1438.

65. Pathirana D, Ormerod AD, Saiag P, Smith C, Spuls PI, Nast A, et al European S3-Guidelines on the systemic treatment ofpsoriasis vulgaris J Eur Acad Dermatol Venereol. 2009;23 Suppl 2:5-70.

66. Smith CH, Anstey AV, Barker JNWN, Burden AD, Chalmers RJG, Chandler DA, et al. British Association of Dermatologists' guidelines for biologic interventions for psoriasis 2009. Br J Dermatol. 2009;161:987-1019.
Biologics: Targets \& Therapy

\section{Publish your work in this journal}

Biologics: Targets \& Therapy is an international, peer-reviewed journal focusing on the patho-physiological rationale for and clinical application of Biologic agents in the management of autoimmune diseases, cancers or other pathologies where a molecular target can be identified This journal is indexed on PubMed Central, CAS, EMBase, Scopus

\section{Dovepress}

and the Elsevier Bibliographic databases. The manuscript management system is completely online and includes a very quick and fair peerreview system, which is all easy to use. Visit http://www.dovepress. com/testimonials.php to read real quotes from published authors. 